\title{
Por que morreu VMS? Sentinelas do des- envolvimento sob o enfoque socioambiental crítico da determinação social da saúde
}

\author{
Why did VMS die? Sentinels of the de-velopment under the critical \\ social environmental approach of the social determination of health
}

Raquel Maria Rigotto', Ada Cristina Pontes Aguiar²

RESUMO Partiu-se do óbito de trabalhador em empresa transnacional por hepatopatia causada por agrotóxicos, para debater limites do paradigma biomédico que orienta as ações do Sistema Único de Saúde. Com base no enfoque socioambiental crítico e transformador, busca-se alargar a compreensão desta e de outras mortes de trabalhadores, 'incluídos' por meio do emprego precarizado e desigualmente protegidos pelas políticas públicas. Caracteriza-se, então, um processo de vulnerabilização mediado pelo Estado neoliberal e tensionam-se as bases teórico-metodológicas da saúde coletiva para avançar em uma perspectiva crítica e emancipatória, em diálogo com os saberes de outros sujeitos epistêmicos e políticos.

PALAVRAS-CHAVE Saúde do trabalhador. Saúde e ambiente. Políticas públicas.

\begin{abstract}
We start from a transnational company worker who died of liver disease caused by pesticides, to discuss limits of the biomedical paradigm that guides the actions of the Unified Health System. Based on the critical and transformative social environmental approach, we seek to expand the understanding of this and other deaths of workers 'included' through precarious jobs and unequally protected by public policies. It features a vulnerability process mediated by the neo-liberal state and its extrativist policies of development, and enhance the theoreticalmethodological bases of public health to advance critical and emancipatory perspective, in dialogue with the knowledges of other epistemic and political subjects.
\end{abstract}

KEYWORDS Occupational health. Environment health. Public policies.

\footnotetext{
1 Universidade Federal do Ceará (UFC), Faculdade de Medicina - Fortaleza (CE), Brasil.

raquelrigotto@gmail.com

2 Universidade Federal do Cariri (UFCA), Faculdade de Medicina - Juazeiro do Norte (CE), Brasil.

adacristinapa@gmail.com
} 


\section{Introdução}

VMS era um jovem trabalhador agrícola, que, durante os últimos três anos de sua vida, trabalhou na empresa de fruticultura Del Monte Fresh Produce Brasil Ltda., situada no Baixo Vale do rio Jaguaribe (municípios de Limoeiro do Norte e Quixeré), no Ceará. Ele desenvolveu uma doença hepática que o levou ao óbito aos 31 anos de idade. O laudo emitido por pesquisadores da Faculdade de Medicina da Universidade Federal do Ceará (UFC) apontou a 'hepatopatia grave de provável etiologia induzida por substâncias tóxicas' - agrotóxicos, no caso - como a causa mortis (RIGOTTO; LIMA, 2010).

O nexo do agravo com o trabalho foi reconhecido pelo Tribunal Regional do Trabalho no Ceará, obrigando a empresa ao pagamento de danos materiais e morais ${ }^{1}$. Bochner (2015) toma esse caso como um 'evento sentinela' e, a partir dele, propõe:

[...] um novo modelo de vigilância e captação de dados, a fim de incentivar e instrumentalizar as vigilâncias dos municípios a atuar na fiscalização das condições de trabalho e, se possível, realizar busca ativa de casos de intoxicação crônica por agrotóxicos. (BOCHNER, 2015, P. 10).

Por concordar com Bochner que o óbito de VMS é um evento sentinela que demanda e orienta o desencadeamento de ações preventivas relevantes para um amplo conjunto de pessoas expostas aos agrotóxicos, objetiva-se, neste texto, aprofundar a leitura desse evento, no intuito de alargar a compreensão dos diferentes elementos envolvidos na produção social dessa (e de outras) morte e de instigar o debate sobre as políticas públicas responsáveis por garantir o papel constitucional do Estado na proteção da saúde.

Adotou-se, como referencial teórico, o enfoque socioambiental crítico e transformador da determinação social da saúde (PORTO; ROCHA; FINAMORE, 2014), que se baseia na teoria da determinação social do processo saúde-doença, construída a partir da medicina social latino-americana, nos anos 1970, sobre

os marcos do materialismo histórico, adotando categorias de análise como reprodução social, classe social, ideologia, produção econômica, cultura, etnia e gênero. (PORTO; ROCHA; FINAMORE, 2014, P. 4072).

Ao mesmo tempo, o enfoque proposto reconhece novos elementos contemporâneos dos contextos histórico, econômico, político e social que tensionam as bases teórico-metodológicas da saúde coletiva: considera especialmente a magnitude e gravidade da crise socioambiental desencadeada pela:

[...] globalização e o crescimento do neoextrativismo na periferia global, [que] intensificam a demanda por novos territórios e recursos naturais à economia, resultando em significativos impactos sobre os ecossistemas e a vida das populações vulnerabilizadas. (PORTO; ROCHA; FINAMORE, 2014, P. 4071).

Busca, então, aportes em diferentes campos do conhecimento e experiências:

- A 'Ecologia Política' que, ao estudar os conflitos ecológicos distributivos (MARTINEZALIER, 2007) ou conflitos ambientais, lança luz sobre as desigualdades e injustiças ambientais (COLETIVO BRASILEIRO DE PESQUISADORES SOBRE A DESIGUALDADE AMBIENTAL, 2013) produzidas pela assimetria de poder político entre os agentes econômicos e os povos afetados nos processos de disputa pela terra e suas riquezas e consignadas na expansão agrícola, minerária e nas obras de infraestrutura sobre seus espaços de vida e reprodução social.

- A 'Geografia Política e da Saúde', que oferece novas possibilidades de ampliar a compreensão da relação (de poder) das sociedades humanas com o espaço e os
1 Processo no AP-012850074.2009.5.07.0026, movido pela viúva do trabalhador, com apoio da Rede Nacional de Advogados e Advogadas Populares (Renap) (Dr. Cláudio da Silva Filho e Dra. Patrícia de Oliveira Gomes). 
2 "Ao buscar esse óbito no Sistema de Informação sobre Mortalidade (SIM)23, verifica-se que ele se encontra registrado em 2008, Declaração de Óbito número 12.223.395, na qual consta como causa básica Insuficiência Hepática Aguda e Subaguda (K72.0) e como causas relacionadas Insuficiência Renal

Aguda não Especificada (N17.9) e Hematêmese (K92.0). [...] Nada se pode afirmar sobre a circunstância do evento, uma vez que as variáveis 'circunstância do óbito' e 'acidente de trabalho' não foram preenchidas. Chama a atenção o fato de que, entre as causas apresentadas, os agrotóxicos não foram sequer mencionados" (BOCHNER, 2015, P. 3). ecossistemas, por meio de conceitos como território, territorialidades, (des)territorialização (HAESBAERT, 1997), entre outros, permitindo avaliar melhor as consequências da imposição da lógica capitalista - com seus tempos, racionalidades e riscos tecnológicos relacionados com os processos produtivos - sobre os modos de vida de comunidades tradicionais, povos indígenas, negros e camponeses, entre outros, definidos a partir de seus ecossistemas e culturas.

- O campo da 'Sociologia' traz noções como espaço social e habitus (BOURDIEU, 2007), que abrem horizontes para integrar às análises a dimensão simbólica e cultural dos conflitos ambientais e as possibilidades de agência dos afetados, superando a perspectiva economicista e o

fosso existente entre o plano macroestrutural e coletivo, e as condições e potencialidades dos sujeitos em planos mais pessoais e comunitários. (PORTO; ROCHA; FINAMORE, 2014, P. 4073).

- As ‘Teorias Descoloniais', que denunciam a perversa persistência da colonialidade do ser, do saber e do poder - mesmo após a independência política dos povos da América Latina, África e Ásia - e suas articulações com o padrão mundial da dominação capitalista e racista, ao tempo que reclamam o reconhecimento da rica diversidade cultural desses povos, a valorização de seus saberes e conhecimentos e de sua condição de sujeitos epistêmicos por meio de uma ecologia de saberes (SANTOS; MENESES, 2010).

Assim, o enfoque socioambiental crítico e transformador se insere em uma epistemologia política de natureza pluriepistêmica (PORTO, 2011) e assinala a necessidade de ir além dos paradigmas biomédico e epidemiológico, para integrar "questões de saúde e ambiente aos direitos humanos, territoriais e sociais" (PORTO; ROCHA; FINAMORE, 2014, P. 4075).

Ao adotar essa perspectiva, será percorrido, neste texto, o evento sentinela da morte do trabalhador VMS desde a abordagem da clínica até o contexto social, econômico e político em que ele acontece. Na primeira parte, será apresentado o caso clínico, o qual será discutido em diálogo com as políticas públicas de saúde em vigor. Na segunda parte, será ampliado o leque de leitura dos alertas que o caso de VMS traz, se analisado no contexto mais amplo de sua determinação social.

\section{Para estabelecer o nexo entre o agravo e a ocupação}

O caso de VMS foi conhecido não por meio dos serviços de atenção à saúde do Sistema Único de Saúde (SUS), da vigilância epidemiológica ou dos sistemas de informação sobre agravos à saúde ${ }^{2}$, mas de um militante inserido no movimento sindical dos servidores públicos do município de Limoeiro do Norte. Vizinho de VMS, sabedor de seu trabalho e atento aos debates públicos sobre os impactos dos agrotóxicos sobre a saúde, o militante considerou suspeito o diagnóstico de hepatite viral realizado pela empresa e procurou a equipe da UFC que desenvolve pesquisas na região - em uma atitude que abre espaço para considerar o papel dos sujeitos locais na vigilância da saúde (ALVES, 2013).

A metodologia de investigação do caso envolveu:

- Estudo da história clínica a partir dos prontuários das internações hospitalares de VMS (Hospital São José de Doenças infecciosas - HSJ e Hospital Universitário Walter Cantídio - HUWC, da Universidade Federal do Ceará), disponibilizados pela viúva de VMS;

- Estudo da história ocupacional de VMS a partir de anamnese realizada com colega de trabalho que exercia a mesma função e no mesmo período em que VMS trabalhou 
na empresa. A história ocupacional constou de informações sobre o processo de produção, a função exercida pelo paciente, as condições e organização do trabalho, a exposição a riscos à saúde e as medidas preventivas existentes. A entrevista foi gravada, com duração de aproximadamente 2 horas, e foi facilitada pela apresentação de fotografias realizadas pela equipe de pesquisa durante visita para estudo do processo de trabalho e seus riscos na empresa anteriormente ao óbito;

- Estudo bibliográfico sobre a toxicologia dos ingredientes ativos de agrotóxicos e fertilizantes químicos utilizados na empresa, com base nos dados disponíveis no Estudo de Impacto Ambiental da empresa e os colhidos em campo pelo grupo de pesquisa e com auxílio de especialistas da Agência Nacional de Vigilância Sanitária (Anvisa);

- Análise de dados epidemiológicos relativos à saúde dos trabalhadores na empresa com base na pesquisa de Alexandre (2009).

\section{História clínica}

VMS era um paciente do sexo masculino, 31 anos, previamente hígido, negava o uso de medicamentos de rotina, tabagismo, etilismo e o contato com drogas ilícitas. Após três anos de trabalho no almoxarifado químico de empresa do ramo da fruticultura irrigada, evoluiu com a agudização de um provável diagnóstico de hepatopatia crônica, apresentando os seguintes sinais e sintomas: icterícia, astenia, anorexia, cefaleia, febre acima de $38^{\circ} \mathrm{C}$, vômitos pós-prandiais amarelados, colúria, acolia fecal, perda de aproximadamente $10 \mathrm{Kg}$ em um mês, prurido intenso em todo o corpo, episódios de epistaxe, empachamento e pirose.

Após internamento no HSJ, foram descartadas as etiologias infecciosas para explicar o quadro. O paciente foi então transferido para o HUWC, com o intuito de dar prosseguimento à investigação. Durante período em que esteve nesse serviço, houve agravamento do quadro de insuficiência hepática, evoluindo para encefalopatia hepática, culminando com uma síndrome hepatorrenal, distúrbios de coagulação, hemorragia digestiva alta (apresentava varizes esofágicas de médio calibre), choque hipovolêmico e óbito.

\section{História ocupacional}

O paciente era agricultor e trabalhou por 3 anos e 6 meses na Del Monte Fresh Produce Brasil Ltda., produtora de abacaxi para exportação, tendo apontada em sua Carteira de Trabalho e Previdência Social a função de Trabalhador Rural. Foi lotado no almoxarifado químico, onde permaneceu até o afastamento devido à doença que o levou ao óbito.

Esse almoxarifado químico consistia em galpão coberto, fechado lateralmente por paredes de alvenaria ou por telas metálicas. Parte dele destinava-se ao armazenamento dos fertilizantes e agrotóxicos que a empresa utilizava, e outra parte era destinada ao setor de mistura, onde eram preparadas as caldas tóxicas.

O fluxograma da produção nesse galpão partia de uma guia que orientava os produtos a serem utilizados na preparação das caldas tóxicas, bem como a quantidade de cada um. O responsável fazia a conferência e a liberação dos produtos, que então eram separados e transportados ao setor de mistura. Lá os componentes eram adicionados em tambores, misturados e, através de mangueiras, abasteciam o nursey - depósito que acompanha o trator em spray-boom para realizar a pulverização em campo (figura 1). 


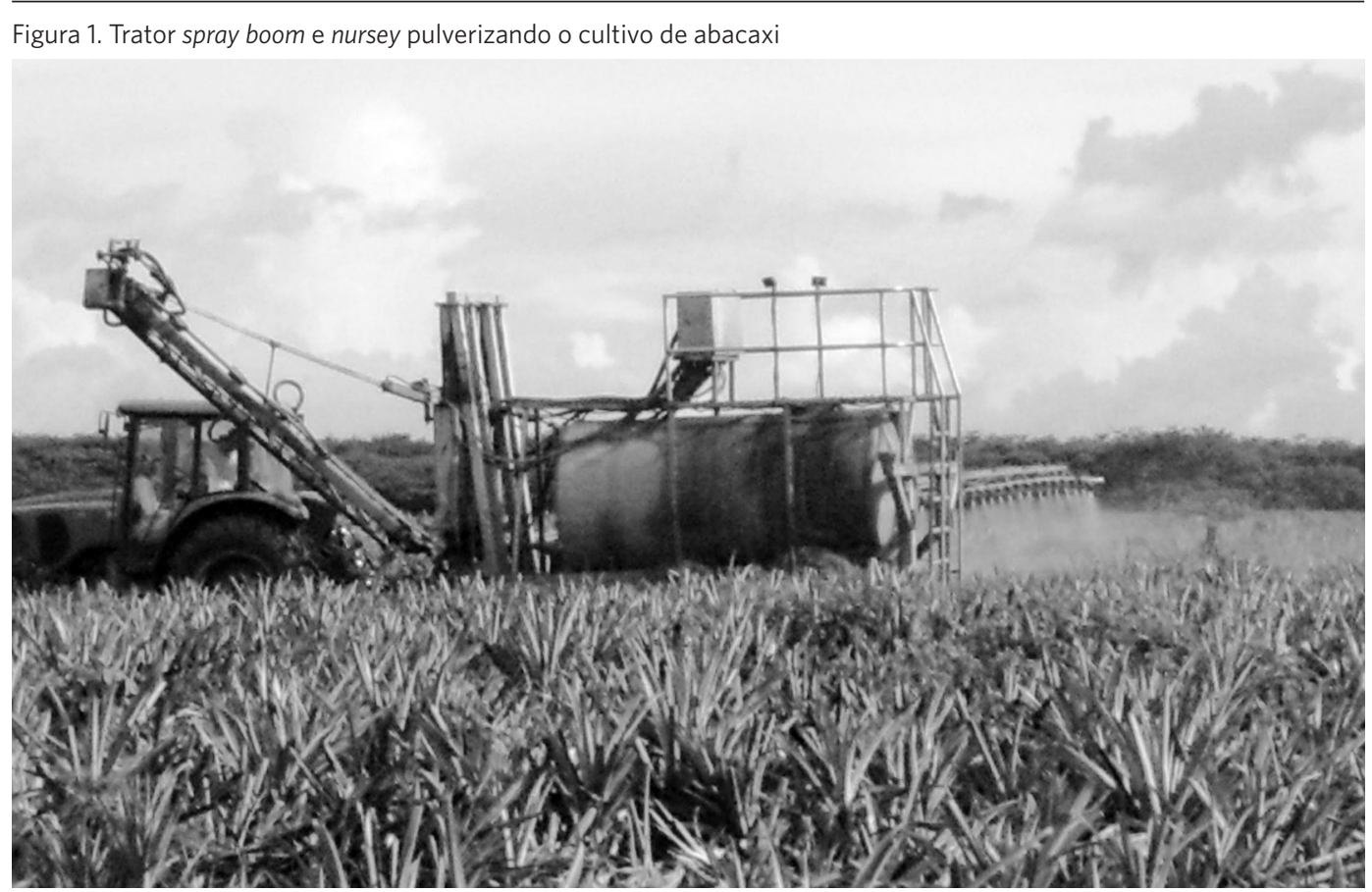

Fonte: Acervo de pesquisa.

A tarefa do trabalhador consistia em atender às requisições de fertilizantes e agrotóxicos. Ele separava os produtos, de acordo com a especificação e a quantidade indicadas na guia, para repassá-los ao setor de mistura. Os produtos manipulados se apresentavam nas formas líquida, gasosa ou em pó. Os líquidos eram retirados de bombonas equipadas com torneiras; os sólidos eram pesados; e o gás estava armazenado em cilindros, que eram atrelados em trator. Fazia ainda parte de sua tarefa guardar no estoque o restante do produto cuja embalagem fora aberta e não totalmente utilizada, assim como receber devolução de produtos liberados e não utilizados. O exercício de sua tarefa exigia o trânsito através do galpão, passando inclusive pelo setor de mistura, onde a contaminação do ar era maior. Entretanto, na avaliação do colega de trabalho entrevistado, todo o galpão apresentava contaminação, tendo em vista as divisórias em telas metálicas. 
Figura 2. Tarefa de dosagem de fertilizantes e agrotóxicos, análogas às realizadas pelo trabalhador em estudo

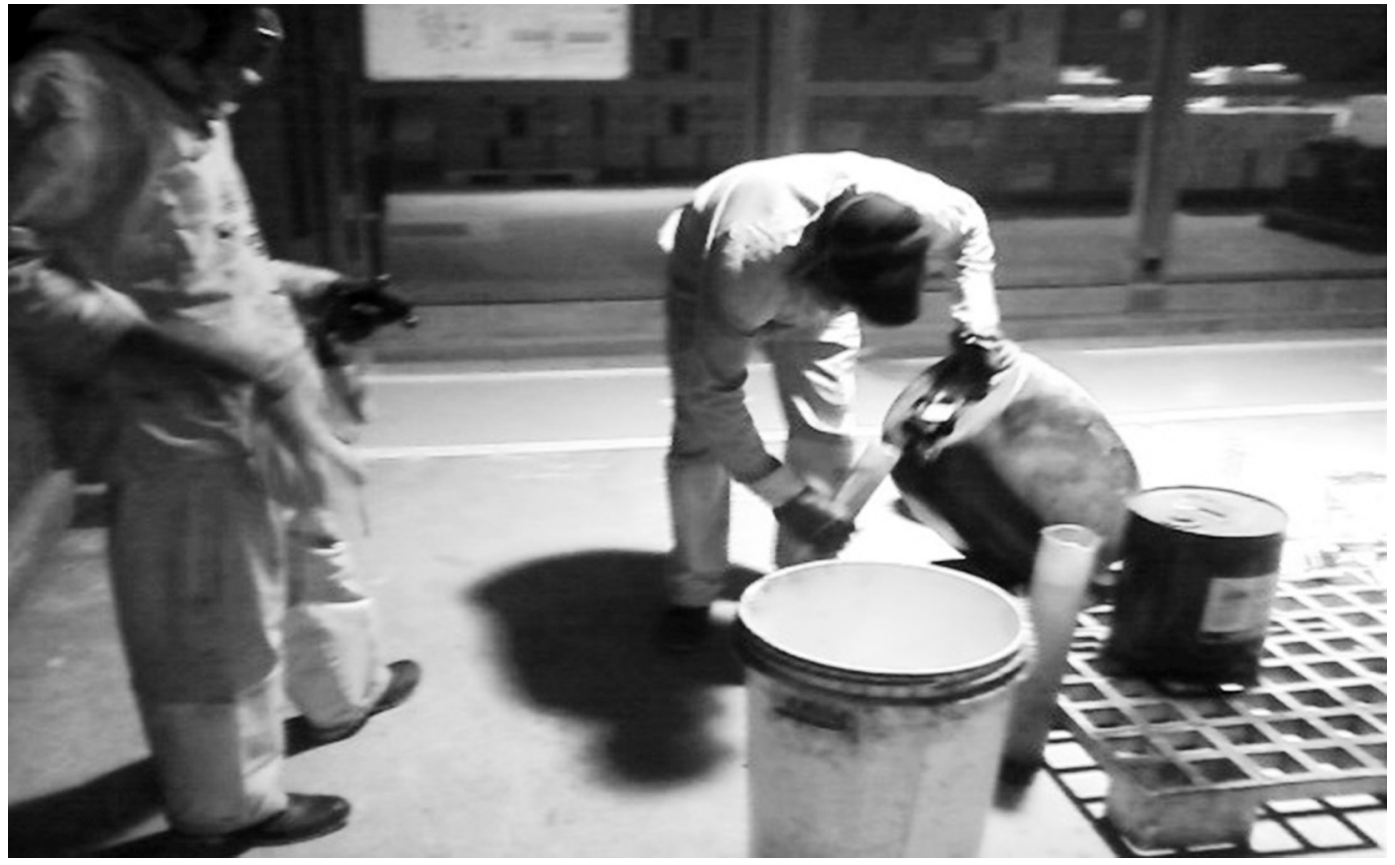

Fonte: Acervo de pesquisa.

Os ingredientes ativos de agrotóxicos utilizados e citados pela empresa, de acordo com o Estudo de Impacto Ambiental (EIA), são: Herbicidas - Bromacil e Diuron; Inseticidas: Carbaryl, Beta-Cyflithrin, Bacillus Thuringiensis, Imidacloprid; Fungicidas: Triadimefon, Thiabendazole, Tebuconazole, Fosetyl; Desfoliante: Ethephon. Sabe-se, entretanto, que a prescrição de ingredientes ativos nesses processos produtivos é bastante dinâmica, respondendo ao surgimento de novas pragas ou novos ingredientes ativos, ao desenvolvimento de resistência, preços e disponibilidade no mercado, entre outros. Há informes dos trabalhadores de que, além dessas, a empresa utilizava outras substâncias que, por restrições no comércio internacional, não foram informadas no EIA. Pode-se estimar que, a cada noite, eram preparados cerca de 15 tanques de calda tóxica, cada um contendo 5.680 litros, totalizando 85.200 litros.

Sua jornada de trabalho era de 8 horas diárias, de segunda a sábado, sempre no período noturno. Entretanto, era praticamente a regra trabalhar pelo menos mais 2 horas extras diárias, totalizando 10 horas de trabalho por dia e 60 horas semanais. No início de seu trabalho na empresa, essa jornada pode ter sido maior:

Logo no início, quando a gente começou a gente trabalhava mais do que 11 horas, tinha dias que a gente entrava na fazenda 5 horas da tarde, às vezes nós saia da fazenda era 7 horas da manhã. (Colega de trabalho informante).

A empresa fornecia Equipamentos de Proteção Individual (EPI) com regularidade, embora houvesse algum trâmite burocrático mais lento para o acesso aos mesmos pelos trabalhadores noturnos.

Mas ele [VMS] nunca deixou de trabalhar com máscara, ele nunca deixou de trabalhar com EPI, nunca! Era um cara que todo mundo se admirou dele, porque era um cara que sempre se preveniu. Outra coisa, se ele fosse jantar ou se ele fosse 
fazer um lanche, lavava as mãos, era tudo bem direitinho, aquilo ali dele certo. (Colega de trabalho informante).

A rotina estabelecida pela empresa para a troca de filtros das máscaras respiratórias, de filtro químico, era mensal, independentemente da exposição: "a gente percebia o filtro todo preto por dentro, principalmente quem trabalha fazendo mistura" (colega de trabalho informante).

Os exames médicos eram realizados periodicamente, constando de exame clínico sumário que, segundo o informante, "não levava nem um minuto", e dosagem semestral da atividade da acetilcolinesterase e de plaquetas. Ainda de acordo com o colega de trabalho:

Eles não te dão nem a cópia [dos resultados dos exames] né, pelo menos uma guiazinha! Eu falo: rapaz... porque eles não dão um parecer pra gente, aí eles dizem 'é ordem da empresa, a empresa não pode dar nada aqui não'. (Colega de trabaIho informante).

\section{Discussão do caso clínico: o nexo entre o agravo e a exposição ocupacional}

Embora um grande número de produtos químicos industrializados seja reconhecido como hepatotoxinas, doença hepática por exposição ocupacional a eles é raramente suspeitada e diagnosticada (MALAGUARNERA ET AL., 2012).

A consulta às monografias sobre os ingredientes ativos com os quais o trabalhador teve contato direto, depositadas na Anvisa - Ministério da Saúde, evidenciou que há descrição de hepatotoxicidade para a maior parte deles. Os danos hepáticos são classificados como agudos e/ou crônicos. Entre as alterações agudas, e os respectivos ingredientes ativos relativos a elas, pode-se citar: hepatomegalia (Diuron), indução de enzimas cromossomiais hepáticas (Deltamethrin), alteração da função hepática (Deltamethrin e Bacillus thurigiensis), colestase e danos no parênquima hepático (Thiabendazole), congestionamento e edema hepático (Imidacloprid). Os efeitos crônicos reconhecidos são: hipertrofia dos hepatócitos (Deltamethrin, Triadimefon), hiperplasia hepática, formação de tumores benignos e malignos (Deltamethrin); congestão e hepatomegalia (Bromacil); possível carcinogenicidade, carcinoma e adenoma hepatocelular (Tebuconazole); aumento do peso hepático (Thiabendazole, Triadimefon), adenoma (Triadimefon).

No caso em análise, as sorologias para hepatites B e C não revelaram hepatites virais. Outras etiologias que entrariam no diagnóstico diferencial seriam: doença biliar, alcoolismo e esteatose hepática não alcoólica (NASH). O Ultrassom abdominal não mostrou lesões sugestivas de doença biliar e de NASH. Hepatite alcoólica fica prontamente descartada dos diagnósticos diferenciais, pois o paciente não apresentava exposição ao álcool.

A hipótese de hepatite autoimune era plausível, mas, de acordo com os critérios internacionais de hepatite autoimune (alvarez et Al., 1999), o paciente não atingiu sequer 10 pontos nesse escore, afastando também essa hipótese diagnóstica. $\mathrm{O}$ diagnóstico de colangite esclerosante também pode ser descartado, pois a ultrassonografia realizada não mostrou alterações das vias biliares. Além disso, os autoanticorpos relacionados com a colangite esclerosante, pANCA, apresentaram resultados negativos, e as enzimas canaliculares não mostraram alterações compatíveis.

A apresentação clínica da doença hepática ocupacional pode ser aguda, subaguda ou crônica, mas é frequentemente insidiosa. Sinais e sintomas de hepatite tóxica incluem: icterícia, prurido, dor subcostal direita, fadiga, anorexia, náuseas, vômitos, rash, perda de peso e colúria. Na forma aguda da 
doença, o quadro clínico é muito semelhante à hepatite viral com rápida deterioração clínica, causada por disfunção hepática grave, encefalopatia e coagulopatia (MALAGUARNERA ET AL., 2012). Essa descrição em tudo se identifica com o caso aqui relatado.

Três critérios devem ser observados para o diagnóstico de hepatite tóxica ocupacional: 1) o dano hepático deve ocorrer após a exposição ao agente químico, portanto a história ocupacional do paciente é necessária; 2) as enzimas hepáticas devem, no mínimo, dobrar o limite superior da normalidade e 3) outras causas de doença hepática devem ser excluídas (MALAGUARNERA ET AL., 2012). Esse paciente preenche todos os critérios mencionados.

Estudos na mesma localidade de onde o paciente procedia já haviam mostrado alterações nas enzimas hepáticas na população trabalhadora da mesma empresa (ALEXANDRE, 2009). No presente relato, esse paciente apresentava elevação de todas as provas de função hepática.

Outros trabalhos já haviam demonstrado elevações enzimáticas do fígado com exposição a agrotóxicos. Na avaliação da incidência de suicídios e sua relação com agrotóxicos no município de Luz, Minas Gerais, Meyer e Resende (2007) entrevistaram 50 moradores, dos quais $98 \%$ referiam uso regular de agrotóxicos. A dosagem de transaminases apresentou elevação em $33,33 \%$, sendo a maior parte acima de $20 \%$ dos valores de normalidade.

Em estudo de caso de um agricultor de 75 anos com história de exposição ocupacional a herbicida e sem história de uso de álcool, drogas de abuso ou medicamentos, Elefsiniotis et al. (2007) encontraram aumento de enzimas celulares, transaminases e canaliculares, GGT e FA, sem a presença de marcadores para hepatites virais (A, B, C, Epstein Barr, citomegalovírus, herpes simples e herpes zoster). Ao exame histopatológico do mesmo trabalhador, foi observado colestase e toxicidade hepatocelular do fígado, compatível com hepatotoxicidade induzida por drogas. Peiró (2007), em relato de caso de agricultor exposto a herbicida paraquat e diquat com queixa de dor abdominal e hepatomegalia ao exame físico, destaca a mesma correlação de aumento de enzimas hepáticas celulares e canaliculares com colestase intra-hepática em duas biópsias, sem sinais de injúria por álcool e sem a presença de autoanticorpo ou anticorpos para hepatite A, B e C.

A Organização Pan-Americana de Saúde (1996) destaca, entre as várias manifestações crônicas relacionadas com os agrotóxicos, as lesões hepáticas com alterações das transaminases e da fosfatase alcalina. Em análise do estado de saúde de agricultores que trabalhavam em cultivo de algodão, Jonnalagadda et al. (2010) avaliam 300 trabalhadores que usavam pesticidas organofosforados e 300 indivíduos como caso controle, com base em parâmetros bioquímicos (alanino aminotransferase/transaminase glutâmico-pirúvica-ALT/TGP e aspartato aminotransferase/ transaminase glutâmico-oxalacética - AST/ TGO). Na dosagem de AST, houve aumento significativo dos níveis no grupo dos expostos em relação aos não expostos, embora essas variações estivessem pouco acima dos valores normais. Na dosagem de ALT, os resultados não foram significativamente diferentes entre os grupos.

\section{Da clínica à saúde pública}

No aparato jurídico-institucional que vem sendo instituído a partir da Reforma Sanitária, o caso de VMS deveria, formalmente, seguir o seguinte fluxo: Diagnóstico da doença do trabalho $\rightarrow$ tratamento, informação do paciente e notificação do caso $\rightarrow$ vigilância Epidemiológica/ vigilância da Saúde dos Trabalhadores/vigilância da Saúde Ambiental.

Como evidenciam diversos estudos (RIGOTTO; AGUIAR, 2015; PONTES, 2012; DIAS; HOEFFEL, 2005), sua realização, entretanto, tem sido limitada por uma série de dificuldades, algumas delas brevemente apontadas a seguir: 


\section{Diagnóstico da doença do trabalho}

Processos de territorialização na Atenção Básica à Saúde e na Estratégia Saúde da Família (ABS/ESF) pouco consideram os processos produtivos em curso no território, as transformações e os riscos ocupacionais e ambientais que geram, bem como a inserção dos moradores e moradoras no mundo do trabalho, comprometendo a identificação das reais necessidades de saúde da população;

Os programas verticais direcionam a organização da atenção segundo os ciclos de vida e patologias prevalentes, nos quais os agravos relacionados com o trabalho são subdiagnosticados, subnotificados e, portanto, pouco considerados;

A semiologia médica e as ações de assistência raramente levam em conta as relações saúde-trabalho-ambiente, por limitações na formação dos profissionais de saúde, tanto nas universidades como nas capacitações oferecidas aos serviços;

A pressão exercida pelas empresas sobre os profissionais dos Serviços Especializados em Segurança e Medicina do Trabalho nas empresas (SESMT) e também do SUS, para que não estabeleçam o nexo entre o adoecimento e os riscos no trabalho, diante de contextos perversos de precarização das relações de trabalho e de violência no campo;

A dificuldade de acesso aos serviços de saúde, seja por sua localização, seja pelo horário de atendimento incompatível com a jornada de trabalho, ou mesmo a baixa expectativa com a resolutividade do serviço, que desestimulam os trabalhadores e trabalhadoras a procurarem atenção;

A avaliação da exposição aos agrotóxicos é complexa, tendo em vista o elevado número de Ingredientes Ativos (IA) autorizados no País (534) - com toxicidades distintas; a diversidade de formulações comerciais disponíveis (mais de 2 mil); o escasso conhecimento científico disponível sobre a interação entre os diferentes IAs - já que a maioria das exposições são múltiplas; a diversidade de fontes de exposição - alimentar, ocupacional, ambiental etc. (FRIEDRICH, 2013); a ausência de registro de dados sobre a exposição de cada pessoa ao longo da vida; os limites das informações disponíveis sobre o uso de agrotóxicos nos territórios - à exceção de alguns estados que fizeram legislação específica, já que os dados públicos disponíveis são fornecidos diretamente pelas empresas fabricantes de agrotóxicos e não informam sobre o consumo (volume e IAs) por municípios, distritos ou localidades;

A clínica médica, marcada pelo paradigma mecanicista de ciência - positivista, linear, fragmentário, entre outros -, encontra dificuldades para analisar complexamente a etiologia dos agravos e estabelecer nexos com a exposição a riscos ocupacionais e ambientais, colocando-se na dependência de análises toxicológicas que confirmariam o diagnóstico - estas, por sua vez, ainda pouco estruturadas no sistema.

\section{Notificação do caso}

Os serviços de saúde são pressionados por demanda frequentemente superior ao que possibilita o dimensionamento da equipe, gerando sobrecargas que comprometem a qualidade do atendimento e que comprimem o tempo que seria dedicado aos procedimentos de notificação, bem como a qualidade de seu preenchimento;

As relações contratuais de trabalho dos profissionais de saúde resultam em rotatividade, a qual compromete a eficácia das capacitações promovidas pelo sistema de saúde;

As relações do poder local com os serviços, fortalecidas pela descentralização do SUS, podem impor limites aos profissionais para o estabelecimento do nexo entre o agravo e o trabalho ou a contaminação ambiental, que 'incriminaria' empresas, nas quais, inclusive, algumas vezes, os próprios profissionais do SUS também trabalham;

Os profissionais consideram que não percebem os retornos que deveriam ser gerados pela realização das notificações aos serviços e, assim, desmotivam-se a seguir notificando. 


\section{Vigilâncias Epidemiológica, da Saúde dos Trabalhadores e das Trabalhado- ras e da Saúde Ambiental}

Os profissionais da vigilância no SUS, de modo geral, precisam enfrentar diversas dificuldades para acessar as empresas, ambientes de trabalho e trabalhadores(as), desde os meios de deslocamento até a 'permissão' das empresas para o acesso; também não estão articulados aos SESMT das empresas, que funcionam de forma autonomizada;

As ações de vigilância, especialmente da Saúde dos(as) Trabalhadores(as) e da Saúde Ambiental, demandam conhecimentos técnicos amplos e diversificados, de acordo com o ramo de atividades dos empreendimentos, exigindo a constituição de equipes multiprofissionais e independentes, em processo de educação permanente e territorializada;

As ações de vigilância supõem também uma infraestrutura técnica de apoio, regionalizada, principalmente para a realização de análises toxicológicas e de contaminação ambiental, a qual não está ainda suficientemente estruturada no País, tanto quantitativa como qualitativamente;

As ações de vigilância são ainda limitadas pelo reduzido poder jurídico-institucional do SUS para incidir sobre as empresas e efetivamente exigir modificações das condições de trabalho ou das práticas ambientais dessas organizações privadas e pela influência de políticos sobre a gestão e os profissionais;

A possibilidade de articulação intersetorial para potencializar as ações das diferentes instituições afetas à saúde ambiental e dos(as) trabalhadores(as), via de regra, ainda permanece como desafio a ser enfrentado;

$\mathrm{O}$ arcabouço jurídico-institucional que dá sustentação às ações de vigilância traz as marcas do paradigma do uso seguro de agrotóxicos (ABREU, 2014), baseando-se em Valores Máximos Residuais (VMR) ou Limites de Tolerância (LT) e concentrando a prevenção no uso de EPI, os quais não protegem efetivamente a saúde.
Esta breve análise, que não pretende ser exaustiva, já permite identificar os limites do paradigma biomédico e epidemiológico que orienta o desenho das ações de saúde no SUS. Isso não significa que elas não sejam necessárias ou que não devam ser aperfeiçoadas, superando os constrangimentos em suas práticas, pelo contrário, este é um esforço necessário no qual muitos(as) estão envolvidos(as).

Ao levar em conta, todavia, que o Brasil coloca-se como o maior consumidor mundial de agrotóxicos desde 2008, que esse uso intensivo vem sendo expandido pelos mais recônditos territórios do País e vem sendo estimulado pela propaganda, pela assistência técnica pública, pelo campo científico e de formação dos profissionais de ciências agrárias, entre outros elementos, torna-se clara a imensa desproporção entre, de um lado, a geração e a difusão do risco, ampliando veloz e enormemente a população exposta e a intensidade da exposição aos agrotóxicos, e, de outro, as possibilidades de resposta do sistema de saúde, ainda que se consiga superar as dificuldades já identificadas.

No intuito de contribuir para o enfrentamento desse vultoso desafio, reúnem-se, no item seguinte, alguns elementos trazidos pelo enfoque socioambiental crítico e transformador à análise do problema.

\section{A morte de VMS em seu contexto: sentinelas do desenvolvimento}

\section{O modelo de desenvolvimento agrí- cola no semiárido}

Quando VMS completava 10 anos de idade, o então Departamento Nacional de Obras e Saneamento (DNOS) estava iniciando a desapropriação de 13.229,20 hectares na Chapada do Apodi, nos municípios de Limoeiro do Norte e Quixeré, para a implantação do 
Perímetro Irrigado Jaguaribe-Apodi (Pija) (entre outros 38 no semiárido nordestino). Essa política tinha como objetivos introduzir um novo modelo de produção agrária nessa região, via modernização da agricultura e incentivo a culturas agrícolas de maior rentabilidade, com destaque para a fruticultura irrigada, ao tempo que visava minimizar os conflitos agrários, desviando o debate da reforma agrária para os projetos de irrigação. Das 320 famílias agricultoras desapropriadas para a implantação do Pija, apenas 19\% conseguiram seguir produzindo no perímetro, ao contrário das expectativas geradas (FREITAS, 2010). Inicia-se então um profundo processo de desterritorialização, mediado pela expropriação da terra e de menor acesso à água, que alterou as formas de organização econômica e social das comunidades, incidiu sobre sua segurança alimentar e gerou um contingente de trabalhadores até então autônomos. Segundo Teixeira (2011, P. 490):

O trabalhador que tem seu trabalho precarizado nas empresas do agronegócio é o mesmo camponês que foi expulso do campo alguns anos antes para a elas dar espaço e é também quem, ao chegar em casa, ingere água contaminada com agrotóxicos.

Em boa parte, corporações transnacionais voltadas à exportação, tais empresas desenvolvem modelos produtivos baseados no monocultivo por meio da mecanização e do uso intensivo de fertilizantes químicos e agrotóxicos - aplicados inclusive por pulverização aérea. Disso resulta ampla contaminação dos compartimentos ambientais, dos(as) trabalhadores e trabalhadoras e moradores(as) do entorno. Avaliação realizada pelo órgão estadual de gestão de recursos hídricos encontrou $60 \%$ das amostras de água do Aquífero Jandaíra contaminadas (COGERH, 2009), chegando essa proporção a $100 \%$ no estudo realizado pela UFC, em que foram identificados 3 a 10 ingredientes ativos de agrotóxicos em cada amostra (MARINHO, 2010).
Estudo epidemiológico entre trabalhadores agrícolas da região $(n=545)$ demonstrou que $30,7 \%$ deles apresentavam quadro de provável intoxicação aguda por agrotóxicos. Para além disso, 23,1\% do total de trabalhadores relataram três ou mais sintomas de efeitos agudos em pele e mucosas (provável intoxicação aguda); $29 \%$ apresentaram alterações hematológicas e $5-19 \%$, como VMS - apresentaram alterações hepáticas (MACIEL; RIGOTTO; ALVES, 2011). Na empresa em que trabalhou VMS, $48,0 \%$ dos trabalhadores examinados apresentaram alterações laboratoriais das provas hepáticas (TGO, TGP, Gama GT, FA, bilirrubinas) (ALEXANDRE; RIGOTTO; PESSOA, 2011). Em relação às neoplasias, Rigotto et al. (2013), ao realizarem uma análise dos dados secundários referentes a esse agravo, evidenciaram um aumento de $38 \%$ na taxa de mortalidade por câncer nos municípios de Limoeiro do Norte, Quixeré e Russas, em comparação com outros 12 municípios em que predomina a agricultura familiar, nos quais não há uma utilização intensiva de agrotóxicos como nos primeiros.

Estudo conduzido por Ferreira Filho (2013) na mesma região demonstrou alterações cromossômicas em células da medula óssea em $25 \%$ do grupo de trabalhadores expostos a agrotóxicos utilizados no cultivo da banana: aneuploidias; deleções dos cromossomos 5, 7 e 11; monossomia; amplificação do gene TP53 -, anormalidades semelhantes às encontradas nas síndromes mielodisplásicas e nas leucemias mieloides agudas, e importantes para o prognóstico de doenças malignas. Estudando o câncer infantojuvenil no Ceará, Barbosa (2016) identificou que, no período de 2000 a 2011, foram registrados 3.274 casos e 2.080 óbitos em menores de 19 anos, sendo que a tendência temporal das taxas de mortalidade para câncer em Camocim/ Acaraú, Baixo Jaguaribe e Cariri apresentaram aumento na média anual. Na correlação espacial dos casos de câncer com os polos de irrigação, as maiores concentrações de 
casos estão nas microrregiões onde estão instalados os polos de irrigação, tendo sido verificado nos relatos de casos de crianças e adolescentes do Baixo Jaguaribe que o fator de risco para câncer mais presente foi o de exposição a agrotóxicos.

Apesar de todos esses impactos, ao invés de serem sobretaxados como o cigarro e as bebidas alcoólicas, os agrotóxicos contam com isenção fiscal de $100 \%$ dos impostos no Ceará (Decreto $\mathrm{n}^{\mathrm{o}}$ 24.569/1997) - Imposto sobre Operações Relativas à Circulação de Mercadorias (ICMS), Imposto sobre Produtos Industrializados (IPI), Contribuição para Financiamento da Seguridade Social (Cofins) e Programas de Integração Social e de Formação do Patrimônio do Servidor Público (PIS/ Pasep) -, a exemplo do que ocorre em outros estados do Brasil (TEIXEIRA, 2011). Conforma-se então uma política pública de desenvolvimento agrícola que promove, legitima, financia e apoia um modelo que incide negativamente sobre os determinantes da saúde, ao retirar das famílias camponesas o acesso aos bens naturais que provêm sua existência, reorganizar a produção e o trabalho introduzindo riscos de elevado impacto sobre a saúde pública, especialmente desse segmento social. Sem uma avaliação adequada das consequências desse modelo, sua expansão em mais 193.137 hectares está sendo promovida pelo Plano Plurianual 2012-2015 e pela Política Nacional de Irrigação (Lei $n^{0}$ 12.787/2013), a qual aponta o aumento da produtividade e da competitividade do agronegócio entre seus objetivos (PONTES ET AL., 2013). Uma compreensão ampliada do princípio da intersetorialidade do SUS alerta para a necessidade de situar a saúde como direito de todos e dever do Estado "garantido mediante políticas sociais e econômicas que visem à redução do risco de doença e de outros agravos" (BRASIL, 1988), como reza o artigo 196 da Constituição de 1988, e não por políticas como essa.

\section{Precarização do trabalho e resistên- cias dos trabalhadores}

A Del Monte Fresh Produce Brasil Ltda., onde trabalhava VMS, conta com a certificação internacional privada GlobalGAP (Boas Práticas Agrícolas, em inglês), requisito fundamental para o acesso ao mercado europeu, emitida após inspeção de empresas de auditoria, que examinam 234 pontos, em que

117 são vinculados à segurança alimentar, 50 ao meio ambiente e biodiversidade, 46 ao controle da rastreabilidade e 21 relacionam-se diretamente ao bem-estar dos trabalhadores. (BEZERRA, 2012, P. 193).

Em um imaginário social ainda marcado pela colonialidade, essa certificação possivelmente alimenta a ideia de que grandes empresas estrangeiras adotam boas práticas, respeitam a legislação, têm competência técnica e são eficientes. Entretanto, registros do Ministério Público do Trabalho em Limoeiro do Norte apontam depoimentos de 27 trabalhadores dessa empresa sobre o uso de agrotóxicos proibidos no Brasil, os quais, durante as auditorias do GlobalGAP, eram armazenados em um "caminhão-baú amarelo e escondido no mato".

Após aprofundado estudo sobre o trabalho nos perímetros irrigados do Nordeste, Bezerra conclui que:

A realidade do trabalho nos espaços da fruticultura demonstra justamente a persistência da precarização. Os principais problemas relatados fazem lembrar que, embora possamos testemunhar a modernização do processo produtivo por meio das técnicas avançadas de plantio, do uso de sementes geneticamente modificadas etc., quando tratamos das relações de trabalho, todo o empreendimento da modernização se desmorona para erigir práticas arcaicas de superexploração dos trabalhadores mediante: longas jornadas de trabalho, estabelecimento de metas de 
produção; persistência do bóia-fria, inexistência de infraestrutura adequada para a alimentação dos trabalhadores; precariedade do transporte; ambiente de opressão e assédio moral; e riscos para a saúde pela exposição aos agrotóxicos no espaço de trabalho e de moradia. (BEZERRA, 2012, P. 220).

É o que demonstram também outros estudos realizados no Baixo Jaguaribe, onde vivia VMS. De acordo com Ferreira et al. (2011), 71,7\% dos trabalhadores do agronegócio contam com a renda mensal de um a dois salários mínimos. As empresas não remuneram o tempo de deslocamento dos trabalhadores ao trabalho (horas in itinere), e as frequentes horas extra não são opcionais, ao contrário do que prevê a legislação, e aqueles que não aceitam, não têm transporte de volta para casa no horário regular. À extensão da jornada de trabalho, associa-se a imposição de metas de produtividade, alcançadas pela intensificação do trabalho. No caso do cultivo da banana, por exemplo,

cada grupo de três trabalhadores tem que, diariamente, colher e transportar 175 caixas com média de $70 \mathrm{Kg}$ cada, totalizando 12.250 $\mathrm{Kg}$, havendo desconto no seu salário caso a meta não seja atingida. (RENAP, 2012, P. 6).

Tais metas produzem não só o cansaço e o esgotamento de cada dia, mas também o desgaste do estado geral de saúde e o comprometimento do sistema osteomuscular, gerando patologias crônicas que vão limitar a vida desses trabalhadores no presente e no futuro.

Cultivos sazonais como o do melão implicam contratos de trabalho temporários, situação em que estão 45,2\% dos trabalhadores do agronegócio no Perímetro Irrigado Jaguaribe-Apodi - o que não assegura a reprodução da força de trabalho fora dos períodos em que ela é útil à empresa (FERREIRA; TEIXEIRA; MARINHO, 2011). A migração de trabalhadores atraídos para essa atividade é acompanhada por fluxos de exploração sexual e prostituição, inclusive infantojuvenil. Além do sofrimento humano e da disseminação de doenças sexualmente transmissíveis, tal quadro repercute ainda em um índice de gravidez na adolescência três vezes superior à média nacional, como constatou estudo no distrito de Lagoinha, município de Quixeré (PESSOA, 2010). As longas jornadas de trabalho, as precárias condições de trabalho e o escasso tempo com a família são especialmente penosos para as trabalhadoras, que ainda têm socialmente a responsabilidade por uma segunda jornada de trabalho no cuidado com a casa e com os filhos.

A resistência a essa superexploração não tem passado pelo sindicato dos trabalhadores: embora $69,4 \%$ deles sejam sindicalizados - porque a empresa acordou com a entidade que realizaria esse procedimento no momento da contratação -, 79,1\% nunca participaram de atividades do sindicato (FERREIRA; TEIXEIRA; MARINHO, 2011). Ainda assim, os empregados da Del Monte fizeram greve em 2008 e 2012, apoiados por movimentos sociais e por pastorais sociais, reivindicando:

1 - Pagamento das horas in itinere, Art. 58 da CLT.

2 - Fim do assédio moral existente, principalmente com a imposição de metas que ultrapassam a capacidade de trabalho do trabalhador e quanto ao ponto, que precisa de regras de proteção e segurança, pois por qualquer aborrecimento, o fiscal corta o ponto, mesmo o trabalhador tendo trabalhado o dia inteiro.

3 - Fim da obrigatoriedade de fazer horas extras, que estas devem ser eventuais, respeitando a CLT.

4 - Atendimento à solicitação de mudança de setor de mais de 50 trabalhadores que trabalham na adubação e que já possuem parecer do médico da empresa recomendando a mudança, mas que o setor de pessoal não 
realiza, estando estes trabalhando doentes, com doenças adquiridas nesse setor.

5 - Realização de perícia para determinar o grau de insalubridade, pois todos estão expostos a agentes químicos nocivos.

6 - Fornecimento de EPIs, pois estes são insuficientes, caracterizando condições precárias de trabalho.

7 - Fim do porte de facões por parte dos fiscais, pois não é necessário ao trabalho dos fiscais e os trabalhadores se sentem intimidados (Transcrição de panfleto divulgado pelos trabalhadores em greve, acervo de pesquisa).

A quarta reivindicação relaciona-se com o estudo de Ferreira Filho (2013), já mencionado, a partir do qual os trabalhadores que já apresentavam alterações citogenômicas não puderam ser abrigados pela Previdência Social, sob o argumento de que ainda não apresentavam incapacidade para o trabalho ou 'm CID' que justificasse o afastamento. A indicação médica de afastamento do risco também não foi acatada pela empresa, repercutindo em sofrimento psíquico que inclusive levou um dos trabalhadores à tentativa de suicídio. A violência simbólica presente nas relações hierárquicas de trabalho aparece também nas segunda e sétima reivindicações, relacionando o facão especialmente à imposição de horas extra para o cumprimento de metas de exportação acordadas pela empresa com a rede de supermercados Walmart na Holanda (BEZERRA, 2012).

No que diz respeito à atenção à saúde dos trabalhadores, diversos movimentos sociais da região se envolveram em um processo participativo para a criação e elaboração do Plano de Ação, que veio a ser denominado Centro de Referência em Saúde, Trabalho e Ambiente - Ceresta Rural Zé Maria do Tomé, em homenagem ao líder comunitário, lutador por terra e contra a contaminação dos agrotóxicos, assassinado em abril de 2010. A missão do Ceresta, como componente do SUS, foi definida nesse coletivo em

articular e participar ativamente da construção e desenvolvimento de ações no SUS e demais políticas públicas, com vistas a contribuir para o direito à saúde, trabalho decente e ambiente saudável aos trabalhadores e às trabalhadoras rurais. (SESA, 2013, P. 4).

Tal serviço poderia responder às novas necessidades de saúde trazidas pela modernização agrícola em curso nem sempre reconhecidas pelo SUS. Entretanto, até agora, a Secretaria Estadual de Saúde apenas alugou um imóvel na cidade de Limoeiro do Norte e criou três cargos de gestão do Ceresta, mas não providenciou concurso público para os profissionais que executariam as ações de saúde, e nem mesmo a seleção pública específica foi feita, para agilizar o início do funcionamento do Centro. Trabalhadores e trabalhadoras seguem assim sem a atenção adequada a que têm direito, evidenciando o desigual empenho do Estado quando se trata da garantia de direitos da população, se comparado à sua eficácia na atração e sustentação da expansão agrícola.

Se a promessa de geração de empregos constitui-se como legitimação social desses empreendimentos - mas pode ser lida também como "meio de obter vantagens locacionais e livre acesso a recursos ambientais" (ACSELRAD, 2014, P. 94) -, é de questionar as consequências desse emprego sobre a saúde dos trabalhadores e trabalhadoras, sua qualidade de vida e suas implicações para o sistema público de seguridade social.

\section{Considerações finais}

Além de alertar a vigilância em saúde sobre os óbitos por agrotóxicos, a morte de VMS é sentinela de um 'processo de vulnerabilização' (PORTO, 2011) das populações do campo, 
mediado pelo modelo de desenvolvimento para o campo centrado na modernização da agricultura. Nesse contexto, pode ser mais amplamente compreendida a sociogênese do adoecimento e morte de tantos outros trabalhadores e trabalhadoras, 'incluídos' por intermédio de um emprego precarizado e desigualmente protegidos pelo Estado. Embora a leitura do caso de VMS traga especificidades da região semiárida, a mesma lógica está em expansão nos demais biomas e regiões do Brasil e na América Latina, na medida em que o continente vem sendo subordinado nessa divisão internacional do trabalho, da natureza e dos riscos que configura o neoextrativismo agrícola e mineral (GUDYNAS, 2012).

Os elementos trazidos nesta breve análise se articulam de forma hierarquizada: os agentes econômicos do capitalismo avançado, movidos pelo rentismo e pela acumulação por espoliação, forjam e incidem sobre o Estado neoliberal, induzindo políticas de desenvolvimento agrícola que atendem a seus interesses e que incluem o financiamento dos empreendimentos, a preparação da infraestrutura de que necessitam (terra, água, energia, estradas, portos e aeroportos, tecnologia), a flexibilização e desregulamentação de direitos, além da legitimação simbólica sob o mito do desenvolvimento.

A essa proatividade do Estado em favor do grande capital, soma-se a construção política da ineficácia das políticas sociais (saúde, trabalho, ambiente, entre outras) duramente conquistadas, agravada pelo crônico subfinanciamento, os limites do controle social instituído e, mais recentemente, as próprias ameaças ao sistema público e universal de saúde.

Nesse processo, os territórios de vida no campo são desterritorializados e vulnerabilizados, e às populações são impostos os impactos, que muito se expressam no perfil de saúde-adoecimento, relacionando-se não só com acidentes e intoxicações, mas também com uma ampla gama de agravos crônicos, como distúrbios nutricionais, doenças crônicas não transmissíveis, transtornos mentais, os cânceres, distúrbios endócrinos, malformações congênitas, hepatopatias, entre muitos outros. Por outro lado, como sujeitos políticos e históricos, florescem nos territórios movimentos e redes sociais, processos de afirmação e fortalecimento dos modos de vida que lhes são próprios, lutas em defesa dos direitos territoriais e da saúde, como a Campanha Permanente contra os Agrotóxicos e Pela Vida.

Longe da neutralidade, o campo científico participa desse processo por meio da produção de conhecimentos técnico-científicos, seja para amparar a modernização agrícola (produtividade, biotecnologias, agrotóxicos etc.), seja para fomentar alternativas como a agroecologia ou para realizar estudos que subsidiem políticas públicas garantidoras de direitos ou que desvelem os impactos do modelo de desenvolvimento em curso. Ou ainda, ao participar das controvérsias científicas entre seus diferentes segmentos, algumas vezes perpassados por sérios conflitos de interesse.

É este macrocontexto de ameaças à vida no planeta e de produção de desigualdades e injustiças ambientais que tensiona hoje a saúde coletiva a aprofundar a compreensão da determinação social do processo saúde-doença. Acredita-se que a proposta do enfoque socioambiental crítico e transformador pode contribuir em releituras e novas elaborações. A partir delas, pode-se aprender mais, por exemplo, com os eventos sentinela e, como trabalhadores do campo da saúde coletiva na pesquisa, na formação e nos serviços, avançar na 'vigilância do desenvolvimento' (PIGNATI; MACHADO, 2011), em uma perspectiva crítica e emancipatória, para fomentar as condições históricas e políticas necessárias à preservação da vida e da saúde.

Nesse processo, muito se pode aprender no diálogo com os sujeitos nos territórios, os movimentos e redes sociais em que se organizam. Os povos originários da América Latina, por exemplo, cujos conhecimentos têm sido invisibilizados e desqualificados, 
trazem em suas cosmovisões uma concepção bem diversa da relação sociedade-natureza, que reconhece a interdependência em contraposição ao des-envolvimento. Com seus saberes e experiências, vêm construindo e afirmando 'alternativas ao desenvolvimento', em uma perspectiva descolonial, preservando sementes e apontando pistas para uma vida digna (não é à toa, portanto, que esses povos estão sendo exterminados no neoextrativismo neoliberal contemporâneo). É preciso aproximar-se deles, como sujeitos epistêmicos e políticos que se é - eles e todos.

\section{Colaboradores}

As autoras agradecem a contribuição de Ana Cláudia de Araújo Teixeira, Severino Alexandre, Terezinha do Menino Jesus, José Milton de Castro Lima e Ramon Rawache no estudo do caso clínico apresentado. Agradecem ainda a Reginaldo Araújo pelo exercício da vigilância popular da saúde que permitiu o desocultamento desta morte em sua relação com o trabalho.

\section{Referências}

ABREU, P. H. B. O agricultor familiar e o uso (in) seguro de agrotóxicos no município de Lavras, MG. 2014. 205 f. Dissertação (Mestrado em Saúde Coletiva) - Faculdade de Ciências Médicas, Universidade Estadual de Campinas, Campinas, 2014.

ACSELRAD, H. Disputas cognitivas e exercício da capacidade crítica: o caso dos conflitos ambientais no Brasil. Sociologias. Porto Alegre, ano 16, n. 35, p. 84-105, jan/abr. 2014.

ALEXANDRE, S. F. Exposição a agrotóxicos e fertilizantes: agravos à saúde dos trabalhadores do agronegócio do abacaxi em Limoeiro do Norte-CE. 2009. 156 f. Dissertação (Mestrado em Saúde Pública) Universidade Federal do Ceará, Fortaleza, 2009.

ALVAREZ, F. et al. Autoimmune hepatitis group report: review of criteria for diagnosis of autoimmune hepatitis. J. Hepatol., Copenhagen, v. 31, n. 5, p. 929-938, 1999.

ALVES, P. A. Vigilância Popular da Saúde: cartografia dos riscos e vulnerabilidades socioambientais no contexto de implantação da Mineração de Urânio e Fosfato no Ceará.
2013. 241 f. Dissertação (Mestrado em Saúde Pública) Universidade Federal do Ceará, Fortaleza, 2013.

BARBOSA, I. M. Câncer infantojuvenil: relação com os polos de irrigação no estado do Ceará. 2016. 138 f. Dissertação (Mestrado em Saúde Pública) Universidade Federal do Ceará, Fortaleza, 2016.

BEZERRA, J. E. A fruticultura no Nordeste semiárido: internacionalização, conflitos territoriais e a precarização do trabalho. 2012. 376 f. Tese (Doutorado em Geografia) Universidade Estadual Paulista, São Paulo, 2012.

BOCHNER R. Óbito ocupacional utilizado como evento sentinela. Vigil. sanit. Debate, Rio de Janeiro, v. 3, n. 4, p. 39-49, 2015, Disponível em: <https://visaemdebate. incqs.fiocruz.br/index.php/visaemdebate/article/ view/364>. Acesso em: 15 mar. 2017.

BOURDIEU, P. O Poder Simbólico. 11. ed. Rio de Janeiro: Bertrand Brasil; 2007.

BRASIL. Constituição (1988). Constituição da República Federativa do Brasil. 1988. Disponível em: <http://www. 
planalto.gov.br/ccivil_03/constituicao/constituicaocompilado.htm>. Acesso em: 31 de março de 2015.

\section{COLETIVO BRASILEIRO DE PESQUISADORES DA} DESIGUALDADE AMBIENTAL. Desigualdade ambiental e acumulação por espoliação: O que está em jogo na questão ambiental? E-cadernos CES (Online), v. 17, p. 164-183, 2013. Disponível em: <http://www.ces.uc.pt/ ecadernos/media/ecadernos17/07.ColetivoBras.Pesq. DesigualdadeAmbiental.pdf $>$. Acesso em: 20 fev. 2017.

\section{COMPANHIA DE GESTÃO DOS RECURSOS}

HÍDRICOS (COGERH). Plano de gestão participativa dos aquíferos da bacia Potiguar, Estado do Ceará. Fortaleza: COGERH, 2009. Disponível em: <http://www.srh.ce.gov. br/index.php/constituicoes/category/138-plano-de-gestao-participativa-dos-aquiferos-da-bacia-potiguar-estado-do-ceara\&tmpl=component\&print=1 $>$. Acesso em: 20 fev. 2017.

DIAS, E. C.; HOEFEL, M. G. L. O desafio de implementar as ações de saúde do trabalhador no SUS: a estratégia da RENAST. Ciência \&t Saúde Coletiva, Rio de Janeiro, v. 10, n. 4, p. 817-828, 2005.

ELEFSINIOTIS, I. S. et al. Case Report: Mixed Cholestatic/Hepatocellular Liver Injury Induced by the Herbicide Quizalofop-p-ethyl. Environmental Health Perspectives, Research Triangle Park, v. 115, n. 10. out., 2007.

FERREIRA FILHO, L. I. P. Estudo das alterações citogenômicas da medula óssea de trabalhadores rurais expostos a agrotóxicos. 2013. 84 f. Dissertação (Mestrado em Ciências Médicas) - Faculdade de Medicina, Universidade Federal do Ceará, Fortaleza, 2013.

FERREIRA, M. J. M.; TEIXEIRA, A. A. T.; MARINHO, A. M. C. P. Centralidade do trabalho e sua caracterização nos diferentes contextos de produção agrícola no Baixo Jaguaribe. In: RIGOTTO R. M. (Org.). Agrotóxicos, trabalho e saúde: vulnerabilidade e resistência no contexto da modernização agrícola no Baixo Jaguaribe/CE. Fortaleza: UFC, 2011. p. 296-318.

FREITAS, B. M. C. Marcas da modernização da agricultura no território do Perímetro Irrigado JaguaribeApodi: uma face da atual reestruturação socioespacial do Ceará. 2010. 181 f. Dissertação (Mestrado em Geografia) - Universidade Estadual do Ceará, Fortaleza, 2010.

FRIEDRICH, K. Desafios para a avaliação toxicológica de agrotóxicos no Brasil: desregulação endócrina e imunotoxicidade. Vigilância Sanitária em Debate, Rio de Janeiro, v. 1, n. 2, p. 2-15, 2013. Disponível em: $<$ http://www.visaemdebate. incqs.fiocruz.br/>. Acesso em: 25 abr. 2015.

GUDYNAS, E. Estado compensador y nuevos extractivismos. Nueva Sociedad, Buenos Aires, n. 237, p. 128146, 2012.

HAESBAERT, R. Des-territorialização e identidade: a rede "gaúcha" no nordeste. Niterói: Eduff, 1997.

JONNALAGADDA, P. R. et al. Biochemical alterations of certain health parameters in cotton growing farmers exposed to organophosphorous and pyrethroid insecticides. African Journal of Biotechnology, v. 9, n. 49, p. 8369-8377, 2010. Disponível em: <http://www.ajol.info/ index.php/ajb/article/view/130856/120427>. Acesso em: 20 maio 2016

MACIEL, R. H. M.; RIGOTTO, R. M.; ALVES P. A. Como está a saúde destes trabalhadores? In: RIGOTTO, R. M. (Org.). Agrotóxicos, trabalho e saúde: vulnerabilidade e resistência no contexto da modernização agrícola no Baixo Jaguaribe/CE. Fortaleza: UFC, 2011. p. 391-413.

MALAGUARNERA, G. et al. Toxic hepatitis in occupational exposure to solvents. World J Gastroenterol, Beijing, v. 18, n. 22, p. 2756-2766, 2012.

MARINHO, A. M. C. P. Contextos e contornos da modernização agrícola em municípios do Baixo Jaguaribe-CE: o espelho do (des)envolvimento e seus reflexos na saúde, trabalho e ambiente. 2010. 245 f. Tese (Doutorado em Saúde Pública) - Faculdade de Saúde Pública, Universidade de São Paulo, São Paulo, 2010.

MARTINEZ-ALIER, J. O ecologismo dos pobres: conflitos ambientais e linguagens de valoração. São Paulo: Contexto, 2007. 
MEYER, T. N.; RESENDE, I. L. C. Incidência de suicídios e uso de agrotóxicos por trabalhadores rurais em Luz (MG), Brasil. Revista Brasileira de Saúde Ocupacional, São Paulo, v. 32, n. 116, p. 24-30, 2007.

\section{ORGANIZAÇÃO PAN-AMERICANA DE SAÚDE}

(OPAS). Manual de vigilância da saúde de populações expostas a agrotóxicos. Brasília, DF, 1996. Disponível em: <http://bvsms.saude.gov.br/bvs/publicacoes/livro2.pdf $>$. Acesso em: 20 fev. 2017.

PEIRÓ, A. M. et al. Hepatotoxicity Related to Paraquat and Diquat Absorption Through Intact Skin. Dig Dis Sci., Nova York, v. 52, n. 11, p. 3282-3284, 2007

PESSOA, V. M. Tecendo atenção integral em Saúde Ambiental e Saúde do Trabalhador na Atenção Primária à saúde em Quixeré - Ceará. 2010. 295 f. Dissertação (Mestrado em Saúde Pública) - Universidade Federal do Ceará, Fortaleza, 2010.

PIGNATI, W. A.; MACHADO, J. M. H. O agronegócio e seus impactos na saúde dos trabalhadores e da população do Estado de Mato Grosso. In: MINAYO, C. G.; MACHADO, J. M. H.; PENA, P. G. L. (Org.). Saúde do trabalhador na sociedade brasileira contemporânea. Rio de Janeiro: Editora Fiocruz, 2011, p. 245-272.

PONTES, A. G. V. et al. Os perímetros irrigados como estratégia geopolítica para o desenvolvimento do semiárido e suas implicações à saúde, ao trabalho e ao ambiente. Ciência \&t Saúde Coletiva, Rio de Janeiro, v. 18, n. 11, p. 3.213-3.222, 2013 .

PONTES, A. G. V. Saúde do Trabalhador e Saúde Ambiental: articulando universidade, SUS e movimentos sociais em território rural em conflito socioambiental. 2012. $261 \mathrm{f}$. Dissertação (Mestrado em Saúde Pública) - Universidade Federal do Ceará, Fortaleza, 2012.

PORTO, M. F. S. Complexidade, processos de vulnerabilização e justiça ambiental: um ensaio de epistemologia política. Revista Crítica de Ciências Sociais, Coimbra, v. 93, p. 31-58, 2011.

PORTO, M. F. S.; ROCHA, D. F.; FINAMORE, R. Saúde coletiva, território e conflitos ambientais: bases para um enfoque socioambiental crítico. Ciência \& Saúde

Coletiva, Rio de Janeiro, v. 19, n. 10, p. 4071-4080, 2014.

REDE NACIONAL DE ADVOGADOS E ADVOGADAS POPULARES (RENAP). Denúncia à Secretaria de Direitos Humanos da Presidência da República. Brasília, DF, 3 de julho de 2012.

RIGOTTO, R. M.; AGUIAR, A. C. P. Invisibilidade ou invisibilização dos efeitos crônicos dos agrotóxicos à saúde? Desafios à ciência e às políticas públicas. In: NOGUEIRA, R. P. et al. (Org.). Observatório Internacional de Capacidades Humanas, Desenvolvimento e Políticas Públicas: estudos e análises 2. Brasília, DF: UnB; Fiocruz, 2015. p. 47-90.

RIGOTTO, R. M.; LIMA, J. M. C. Relatório técnico caso Vanderlei Matos da Silva. Fortaleza: UFC, 2010.

RIGOTTO, R. M. et al. Trends of chronic health effects associated to pesticide use in fruit farming regions in the state of Ceará, Brazil. Revista Brasileira de Epidemiologia, Sã Paulo, v. 16, p. 763-773, 2013.

SANTOS, B. S.; MENESES, M. P. (Org.). Epistemologias do Sul. São Paulo: Cortez, 2010.

\section{SECRETARIA DA SAÚDE DO ESTADO DO CEARÁ}

(SESA). Coordenadoria de Políticas e Atenção em Saúde. Núcleo de Atenção à Saúde do Trabalhador. Plano de Ação para Implantação do Centro de Referência em Saúde do Trabalhador e Saúde Ambiental - Ceresta Rural Zé Maria do Tomé. Fortaleza, 2013.

TEIXEIRA, M. M. Chega de segurar o abacaxi: sob a exploração antiga e o discurso moderno do agronegócio, os novos trabalhadores fazem greve. In: RIGOTTO, R. M. (Org.). Agrotóxicos, trabalho e saúde: vulnerabilidade e resistência no contexto de modernização agrícola no Baixo Jaguaribe/CE. Fortaleza: UFC, 2011.

Recebido para publicação em agosto de 2016

Versão final em dezembro de 2016

Conflito de interesses: inexistente

Suporte financeiro: Conselho Nacional de Desenvolvimento

Científico e Tecnológico por meio do Edital MCT/CNPq/MS-

SCTIE-DECIT 24/2006 - Estudos em Populações Expostas à

Contaminação Ambiental, Processo n 409845/2006-0 